International Journal of Biology, Pharmacy and Allied Sciences (IJBPAS) 'A Bridge Betuen Caboratory and QRendor'

www.ijbpas.com

\title{
JUNK FOOD ADVERTISEMENTS AN EVALUATIVE STUDY
}

\section{RENUKA KK ${ }^{1 *}$ AND M. GEETHA ${ }^{2}$}

1: Asst. Professor, Department of Commerce, Sacred Heart College, Autonomous, Thevara, Ernakulam, Kerala

2: Associate Professsor and Research Supervisor, The Cochin College, Kochi 2, Kerala

"Corresponding Author: Dr. Renuka KK: E Mail: renukarajesh7@gmail.com

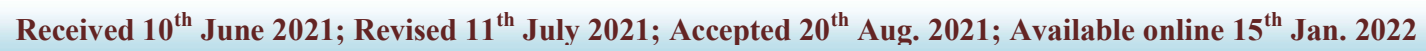

https://doi.org/10.31032/IJBPAS/2022/11.1.1060

\begin{abstract}
Gone are the days, when Indian people used to pack their home-made food wrapped in a banana leaf and the parents and wives were satisfied that their households stay healthy. Now it's the contrasting situation where our young adults feel their tiffin box itself is a discomfort zone. In schools and colleges, our young generation is treated with parlours providing ice cream, coffee and the like and that creates a big threat towards a healthy society. When junk food is consumed very often, the excess fat, added carbohydrates, and processed sugar found in junk food contributes to an increased risk of obesity, cardiovascular disease, and many other chronic health conditions. This descriptive study analyses mothers' attitude towards advertisements of junk food products and evaluates the effects of junk food ads on use of junk foods among children. Mothers who have children in the age group of 10 to 15 have been selected for data collection. This study also aims to explore the harmful effect of food advertising and suggesting various measures to overcome the aftereffects. The sampling method applied for this study is a non-probability convenience sampling technique. The sample size is confined to 100 respondents. A mother who has a child in the age group of 10 to 15 is treated as a single respondent. The sample size is selected from Kochi City.
\end{abstract}

Keywords: Junk food, Food advertisements 


\section{INTRODUCTION}

Gone are the days, when Indian people used to pack their home made food wrapped in a banana leaf and the parents and wives were satisfied that their households stay healthy. Now it's the contrasting situation where our young adults feel their tiffin box itself is a discomfort zone. In schools and colleges, our young generation is treated with parlours providing ice cream, coffee and the like.

Junk food is usually high in added sugars, salt and saturated or Tran's fats. Some evidence points to junk foods as being as addictive as alcohol and drugs. Fast food" is food that is prepared quickly and is eaten quickly or taken out. Although there are a growing number of healthier fast-food options, most fast food can still be classified as junk food. (Christy)

Youth is always misunderstood by their previous generation even in the case of food habits. It's not their fault to follow the trends and patterns that is visible in the society. It's the society that inculcating the trends into the people who reside in it. All are responsible for the functioning of the current system, and our elder generation as more experienced should educate our younger ones what is good and bad in it.

When junk food is consumed very often, the excess fat, simple carbohydrates, and processed sugar found in junk food contributes to an increased risk of obesity, cardiovascular disease, and many other chronic health conditions (wikipedia, 2018). The junk food consumption may create the following health problems among children:

- Memory and learning problems

- Risk of dementia

- Lessens its ability to control appetite

- It makes you impatient and can cause uncontrollable cravings

- Can cause chemical changes that can lead to depression (Desk, 2017)

\section{OBJECTIVES OF THE STUDY}

- To analyse mothers' attitude towards advertisements of junk food products.

- To evaluate the effects of junk food ads on use of junk foods among children.

\section{RESEARCH METHODOLOGY}

- Nature of study - The type of research is descriptive in nature using both primary and secondary data. The area of this research is to study the relationship between junk food marketing and children's physical health. Mothers who have children in the age group of 10 to 15 have been selected for data collection. This study also aims to explore the harmful effect of food advertising and suggesting various measures to overcome the aftereffects.

- Sample Design - The sampling method applied for this study is a non-probability convenience sampling technique. The sample 
size is confined to 100 respondents. A mother who has a child in the age group of 10 to 15 is treated as a single respondent. The sample size is selected from Kochi City.

- Data Collection - The data collection is done using structured questionnaire and personal interview. Apart from this, various secondary sources such as books, magazines, online articles, various research reports, websites etc. are also used for data collection.

- 100 respondents have been selected from kochi city as per the convenience. Each respondent is selected following the criteria that they have at least one child in the age group of 10 to 15.

\section{ANALYSIS AND INTERPRETATION}

Table 1: Cronbach's Alpha

\begin{tabular}{|c|c|c|}
\hline 1. Variable & 2. Cronbach's Alpha & 3. $\quad$ Nof Items \\
\hline Negative attitude towards food advertisements & 5. 0.377 & 6. 4 \\
\hline Positive attitude towards food advertisements & $\begin{array}{ll}\text { 8. } & 0.591\end{array}$ & 9. \\
\hline 10. Effects of advertisements & 0.837 & 12. 6 \\
\hline
\end{tabular}

Source: primary data

To analyze the Indicators of negative which are advertised for (NA2) is an Indicator attitude towards food advertisements. of negative attitude towards food

Parents are asked with different statements to advertisements.

measure their negative attitude towards junk $\mathrm{H}_{3}$ : Ads are not informative source for healthy food advertisements. products (NA3) is an Indicator of negative $\mathrm{H}_{1}$ : Seeing most of the ads are a waste of time attitude towards food advertisements.

(NA1) is an indicator of negative attitude $\mathrm{H}_{4}$ : Advertisements are exaggerated (NA4) is towards food advertisements.

$\mathrm{H}_{2}$ : I don't buy the products for my child an Indicator of negative attitude towards food advertisements.

Table 2: Model Fit Indices For CFA - Negative Attitude Towards Food Advertisements

\begin{tabular}{|c|c|c|c|c|c|c|c|c|c|c|c|}
\hline & $\chi 2$ & DF & P & $\begin{array}{c}\text { Norme } \\
\mathrm{d} \chi 2\end{array}$ & GFI & AGFI & NFI & TLI & CFI & RMR & $\begin{array}{c}\text { RMSE } \\
\text { A }\end{array}$ \\
\hline $\begin{array}{c}\text { Negative attitude } \\
\text { towards food } \\
\text { advertisements }\end{array}$ & $\begin{array}{c}78.61 \\
9\end{array}$ & 30 & 0 & 2.621 & 0.961 & 0.906 & 0.987 & 0.905 & 0.987 & 0.146 & 0.253 \\
\hline Recommended value & & & & $<5$ & $>0.9$ & $>0.9$ & $>0.9$ & $>0.9$ & $>0.9$ & $<1$ & $<1$ \\
\hline \hline
\end{tabular}

\section{Source: primary data}

All the attributes loaded significantly on the model with data. In Table 3 we present the latent constructs. The value of the fit indices regression coefficients.

indicates a reasonable fit of the measurement

Table 3: The Regression Coefficients -Negative Attitude Towards Food Advertisements

\begin{tabular}{|c|c|c|c|c|}
\hline Path & Estimate & $\begin{array}{c}\text { Critical } \\
\text { Ratio } \\
\text { (CR) }\end{array}$ & P & $\begin{array}{c}\text { Variance } \\
\text { explained }\end{array}$ \\
\hline $\begin{array}{c}\text { NA1 } \rightarrow \text { Negative } \\
\text { attitude }\end{array}$ & $\mathbf{0 . 6 5 8}$ & 7.773 & $<0.001$ & 43.3 \\
\hline
\end{tabular}




\begin{tabular}{|c|c|c|c|c|}
$\begin{array}{c}\text { NA2 } \rightarrow \text { Negative } \\
\text { attitude }\end{array}$ & 0.446 & 4.724 & $<0.001$ & 19.9 \\
$\begin{array}{c}\text { NA3 } \rightarrow \text { Negative } \\
\text { attitude }\end{array}$ & 0.521 & 5.690 & $<0.001$ & 27.1 \\
$\begin{array}{c}\text { NA4 } \rightarrow \text { Negative } \\
\text { attitude }\end{array}$ & 0.499 & 5.397 & $<0.001$ & 24.9 \\
\hline
\end{tabular}

Source: primary data

$\mathrm{H}_{1}$ : Seeing most of the ads are a waste of time (NA1) is an indicator of negative attitude towards food advertisements

The results exhibited in Table 3 revealed that the regulatory construct NA1 is an indicator of negative attitude towards food advertisements as the standardised direct effect of this construct on Negative attitude was 0.658 , which is more than the recommended value of 0.4. So, the hypothesis $H_{1}$ is accepted and concludes NA1 is an indicators of negative attitude towards food advertisements

$\mathrm{H}_{2}$ : I don't buy the products for my child which are advertised for (NA2) is an Indicator of negative attitude towards food advertisements

The results exhibited in Table 3 revealed that the regulatory construct NA2 is an indicator of negative attitude towards food advertisements as the standardised direct effect of this construct on Negative attitude was 0.446, which is more than the recommended value of 0.4. So, the hypothesis $\mathrm{H}_{2}$ is accepted and concludes NA2 is an indicator of negative attitude towards food advertisements
$\mathrm{H}_{3}$ : Ads are not informative source for healthy products (NA3) is an Indicator of negative attitude towards food advertisements

The results exhibited in Table 3 revealed that the regulatory construct NA3 is an indicator of negative attitude towards food advertisements as the standardised direct effect of this construct on Negative attitude was 0.521, which is more than the recommended value of 0.4. So, the hypothesis $\mathrm{H}_{3}$ is accepted and concludes NA3 is an indicator of negative attitude towards food advertisements

$\mathrm{H}_{4}$ : Advertisements are exaggerated (NA4) is an Indicator of negative attitude towards food advertisements

The results exhibited in Table 3 revealed that the regulatory construct NA4 is an indicator of negative attitude towards food advertisements as the standardised direct effect of this construct on Negative attitude was 0.499, which is more than the recommended value of 0.4. So, the hypothesis $\mathrm{H}_{4}$ is accepted and concludes NA4 is an indicator of negative attitude towards food advertisements. 


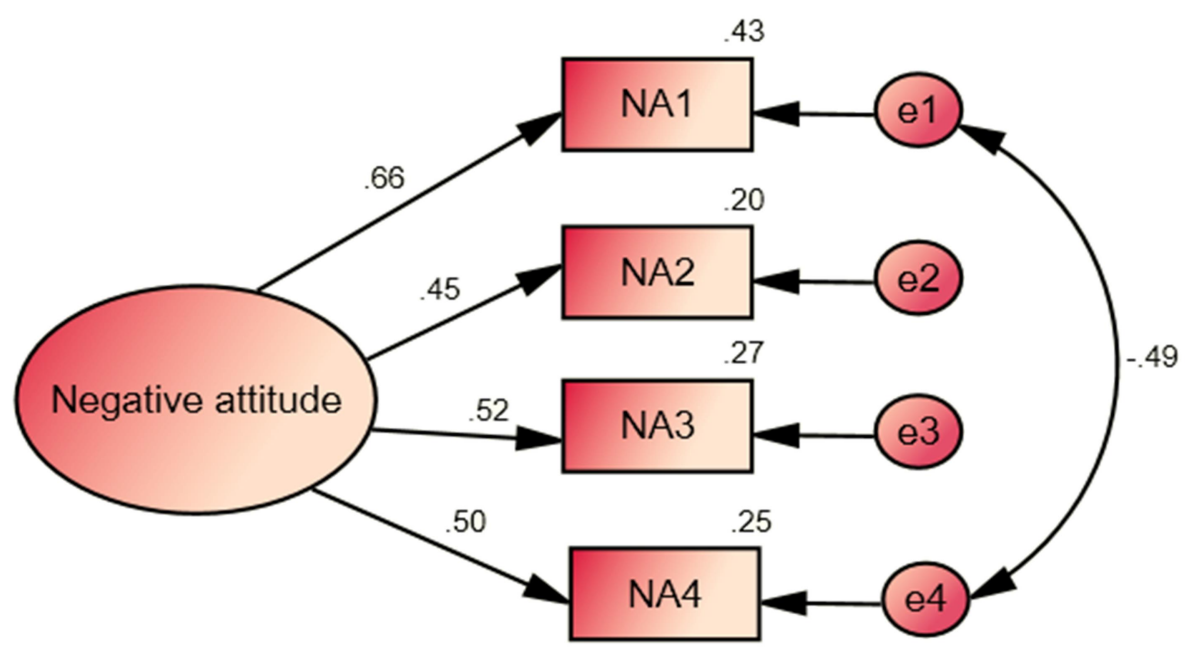

Figure 1:

To analyze the Indicators of positive $\mathrm{H}_{2}$ : Advertisements help to learn new trends in attitude towards food advertisements.

Parents are asked with different statements to measure their positive attitude towards junk food advertisements.

$\mathrm{H}_{1}$ : Advertisement is a valuable source of information (PA1) is an indicator of positive eating habits (PA2) is an Indicator of positive attitude towards food advertisements

$\mathrm{H}_{3}$ : Advertisements helps to select healthy food products for my kid (PA3) is an Indicator of positive attitude towards food advertisements attitude towards food advertisements

Table 4: Model Fit Indices For CFA - Positive Attitude Towards Food Advertisements

\begin{tabular}{|c|c|c|c|c|c|c|c|c|c|c|c|}
\hline & $\chi^{2}$ & DF & P & $\begin{array}{c}\text { Norme } \\
\mathrm{d} \chi^{2}\end{array}$ & GFI & AGFI & NFI & TLI & CFI & RMR & $\begin{array}{c}\text { RMSE } \\
\text { A }\end{array}$ \\
\hline $\begin{array}{c}\text { positive attitude } \\
\text { towards food } \\
\text { advertisements }\end{array}$ & .058 & 1 & .810 & .058 & 1.000 & .998 & .998 & 1.123 & 1.000 & .012 & .000 \\
\hline
\end{tabular}

Source: primary data

All the attributes loaded significantly on the model with data. In Table 5 we present the latent constructs. The value of the fit indices regression coefficients.

indicates a reasonable fit of the measurement

Table 5: The Regression Coefficients -Positive Attitude Towards Food Advertisements

\begin{tabular}{|c|c|c|c|c|}
\hline Path & Estimate & $\begin{array}{c}\text { Critical Ratio } \\
(\text { CR) }\end{array}$ & P & $\begin{array}{c}\text { Variance } \\
\text { explained }\end{array}$ \\
\hline PA1 $\rightarrow$ Positive attitude & $\mathbf{0 . 6 5 8}$ & 7.773 & $<0.001$ & 43.3 \\
PA2 $\rightarrow$ Positive attitude & $\mathbf{0 . 6 7 3}$ & $\mathbf{8 . 0 3 9}$ & $<0.001$ & 45.3 \\
PA3 $\rightarrow$ Positive attitude & $\mathbf{0 . 6 2 8}$ & 7.270 & $<0.001$ & 39.5 \\
\hline
\end{tabular}

Source: primary data

$\mathrm{H}_{1}$ : Advertisement is a valuable source of information (PA1) is an indicator of positive 
attitude towards food advertisements

The results exhibited in Table 5 revealed that the regulatory construct PA1 is an indicator of positive attitude towards food advertisements as the standardised direct effect of this construct on positive attitude was 0.658 , which is more than the recommended value of 0.4 . So the hypothesis $\mathrm{H}_{1}$ is accepted and concludes that Advertisement is a valuable source of information (PA1) is an indicator of positive attitude towards food advertisements $\mathrm{H}_{2}$ : Advertisements help to learn new trends in eating habits (PA2) is an Indicator of positive attitude towards food advertisements

The results exhibited in Table 5 revealed that the regulatory construct PA2 is an indicator of positive attitude towards food advertisements as the standardised direct effect of this construct on positive attitude was 0.673 , which is more than the recommended value of 0.4 .
So the hypothesis $\mathrm{H}_{2}$ is accepted and concludes that Advertisements help to learn new trends in eating habits (PA2) is an indicator of positive attitude towards food advertisements

$\mathrm{H}_{3}$ : Advertisements helps to select healthy food products for my kid (PA3) is an Indicator of positive attitude towards food advertisements

The results exhibited in Table 5 revealed that the regulatory construct PA3 is an indicator of positive attitude towards food advertisements as the standardised direct effect of this construct on positive attitude was 0.658 , which is more than the recommended value of 0.4 . So the hypothesis $\mathrm{H}_{3}$ is accepted and concludes that Advertisements helps to select healthy food products for my kid (PA3) is an indicator of positive attitude towards food advertisements

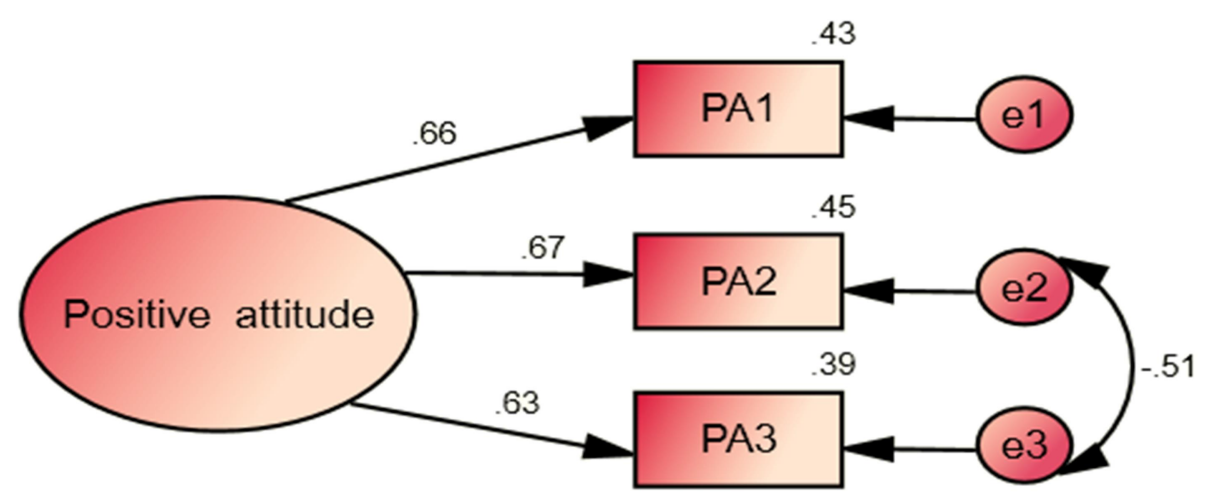

Figure 2:

Source: primary data 
To analyze the Indicators of how watching food ads affects your child. We test the following hypothesis:

$\mathrm{H}_{1}$ : Consuming more junk foods in the place of healthy foods (EA1) is a factor which affects the child on watching food advertisements $\mathrm{H}_{2}$ : Avoiding homely food (EA2) is a factor which affects the child on watching food advertisements $\mathrm{H}_{3}$ : Gradually losing immunity power (EA3) is a factor which affects the child on watching food advertisements

$\mathrm{H}_{4}$ : Getting frequent health problems (EA4) is a factor which affects the child on watching food advertisements

$\mathrm{H}_{5}$ : Not having food in a timely manner (EA5) is a factor which affects the child on watching food advertisements

$\mathrm{H}_{6}$ : Blindly following unhealthy food habits (EA6) is a factor which affects the child on watching food advertisements

Table 6: Model Fit Indices For CFA - Factors Which Affects The Child On Watching Food Advertisements

\begin{tabular}{||c||c|c|c|c|c|c|c|c|c|c|c||}
\hline \hline & $\chi 2$ & DF & P & $\begin{array}{c}\text { Normed } \\
\chi 2\end{array}$ & GFI & AGFI & NFI & TLI & CFI & RMR & RMSEA \\
\hline $\begin{array}{c}\text { Effects of } \\
\text { advertisement }\end{array}$ & 32.370 & 7 & .000 & 4.624 & .954 & .962 & .957 & .939 & .985 & .191 & .191 \\
\hline
\end{tabular}

Source: primary data

All the attributes loaded significantly on the model with data. In table 7 we present the latent constructs. The value of the fit indices regression coefficients. indicates a reasonable fit of the measurement

Table 7: The Regression Coefficients -Factors Which Effects The Child On Watching Food Advertisements

\begin{tabular}{|c|c|c|c|c|}
\hline Path & Estimate & $\begin{array}{c}\text { Critical } \\
\text { Ratio }(\text { CR) }\end{array}$ & P & $\begin{array}{c}\text { Variance } \\
\text { explained }\end{array}$ \\
\hline EA1 $\rightarrow$ Effects of advertisements & $\mathbf{0 . 7 1 3}$ & $\mathbf{8 . 7 9 8}$ & $<\mathbf{0 . 0 0 1}$ & $\mathbf{5 0 . 9}$ \\
EA2 $\rightarrow$ Effects of advertisements & $\mathbf{0 . 7 1 9}$ & $\mathbf{8 . 9 1 9}$ & $<\mathbf{0 . 0 0 1}$ & $\mathbf{5 1 . 7}$ \\
EA3 $\rightarrow$ Effects of advertisements & $\mathbf{0 . 8 1 3}$ & $\mathbf{1 1 . 1 8 6}$ & $<\mathbf{0 . 0 0 1}$ & $\mathbf{6 6 . 1}$ \\
EA4 $\rightarrow$ Effects of advertisements & $\mathbf{0 . 7 6 8}$ & $\mathbf{1 0 . 0 0 1}$ & $<\mathbf{0 . 0 0 1}$ & $\mathbf{5 9 . 0}$ \\
EA5 $\rightarrow$ Effects of advertisements & $\mathbf{0 . 7 4 8}$ & $\mathbf{9 . 5 3 8}$ & $<\mathbf{0 . 0 0 1}$ & $\mathbf{5 6 . 0}$ \\
EA6 $\rightarrow$ Effects of advertisements & $\mathbf{0 . 8 7 8}$ & $\mathbf{1 3 . 4 6 3}$ & $<\mathbf{0 . 0 0 1}$ & $\mathbf{7 7 . 1}$ \\
\hline
\end{tabular}

Source: primary data

$\mathrm{H}_{1}$ : Consuming more junk foods in the place of healthy foods (EA1) is a factor which affects the child on watching food advertisements The results exhibited in Table 7 revealed that the regulatory construct EA1 is a factor which affects the child on watching food advertisements as the standardised direct effect of this construct on Effects of advertisements was 0.713 , which is more than the recommended value of 0.4. So, the hypothesis $\mathrm{H}_{1}$ is accepted and concludes that Consuming more junk foods in the place of healthy foods (EA1) is a factor which affects the child on watching food advertisements.

$\mathrm{H}_{2}$ : Avoiding homely food (EA2) is a factor which affects the child on watching food advertisements

The results exhibited in Table 7 revealed that 
the regulatory construct EA2 is a factor which affects the child on watching food advertisements as the standardised direct effect of this construct on Effects of advertisements was 0.719 , which is more than the recommended value of 0.4 . So, the hypothesis $\mathrm{H}_{2}$ is accepted and concludes that avoiding homely food (EA2) is a factor which affects the child on watching food advertisements.

$\mathrm{H}_{3}$ : Gradually losing immunity power (EA3) is

a factor which affects the child on watching food advertisements

The results exhibited in Table 7 revealed that the regulatory construct EA3 is a factor which affects the child on watching food advertisements as the standardised direct effect of this construct on Effects of advertisements was 0.813, which is more than the recommended value of 0.4 . So, the hypothesis $\mathrm{H}_{3}$ is accepted and concludes that gradually losing immunity power (EA3) is a factor which affects the child on watching food advertisements.

$\mathrm{H}_{4}$ : Getting frequent health problems (EA4) is a factor which affects the child on watching food advertisements

The results exhibited in Table 7 revealed that the regulatory construct EA4 is a factor which affects the child on watching food advertisements as the standardised direct effect of this construct on Effects of advertisements was 0.768 , which is more than the recommended value of 0.4 . So the hypothesis $\mathrm{H}_{4}$ is accepted and concludes that Getting frequent health problems (EA4) is a factor which affects the child on watching food advertisements.

$\mathrm{H}_{5}$ : Not having food in a timely manner (EA5) is a factor which affects the child on watching food advertisements

The results exhibited in Table 7 revealed that the regulatory construct EA5 is a factor which affects the child on watching food advertisements as the standardised direct effect of this construct on Effects of advertisements was 0.748 , which is more than the recommended value of 0.4 . So, the hypothesis $\mathrm{H}_{5}$ is accepted and concludes that Not having food in a timely manner (EA5) is a factor which affects the child on watching food advertisements.

$\mathrm{H}_{6}$ : Blindly following unhealthy food habits (EA6) is a factor which affects the child on watching food advertisements

The results exhibited in Table 7 revealed that the regulatory construct EA6 is a factor which affects the child on watching food advertisements as the standardised direct effect of this construct on Effects of advertisements was 0.878, which is more than the recommended value of 0.4 . So the hypothesis $\mathrm{H}_{6}$ is accepted and concludes that Blindly 
following unhealthy food habits (EA6) is a advertisements.

factor which affects the child on watching food

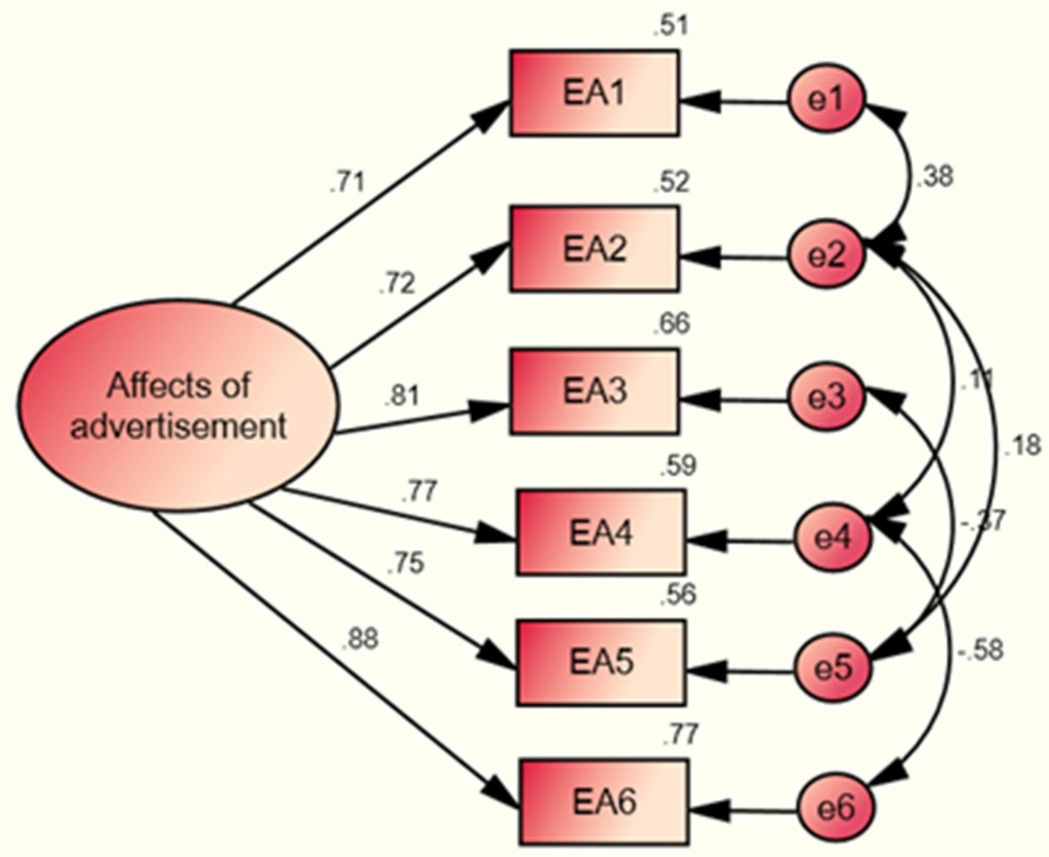

Figure 3:

Source: primary data

\section{FINDINGS OF THE STUDY}

1. Respondents have a negative attitude towards food ads since they feel that it is a waste of time.

2. Mothers are not interested to purchase the food items for their children, particularly which they are constantly watching through different advertisement medias.

3. Respondents have the opinion that food advertisements are not an informative source for selecting healthy foods. It gives misleading information that does not promote healthy foods.

4. Respondents have the opinion that advertisements are exaggerated and magnify the real fact

5. The indicators of positive attitude towards food ads are: advertisement is a valuable source of information and advertisements shows new trends in eating habits.

6. Impact of food advertisements that clearly supported by the mothers are: 
gradually losing immunity power and blindly following unhealthy food habits.

7. The positive attitude towards food advertisements differ among age groups. Age 30-40differs significantly with age group 41-50. But there is no difference among age groups in the case of negative attitude and factors affecting food decisions.

8. The positive attitude towards food advertisements differs among educational qualifications. Post graduates differ significantly with graduates. But there is no difference among educational qualifications in the case of negative attitude and factors affecting food decisions.

\section{CONCLUSION}

This is the era of digitalisation. People use online media for various services and to get information. Companies especially fast-food organisations use digital media for marketing their goods and services in an extensive manner. Digital Interactive technologies and available television channels have made our younger generation as a target group of consumers. Marketers exploit these situations since kids are the most sensitive target group of fast-food products. They watch various advertisements through digital medias and television in an extensive manner without the direct intervention of parents. Children have the tendency to believe all the coloured and flavoured misleading information in the food ads. This may induce the children to follow the new trend of eating habits that are anti thesis of a healthy food behaviour. The end result will be increased rate of obesity, overweight, diabetes and related health issues among the kids. Currently this forms a big threat to our society since today's children are tomorrow's citizens and we need our younger generation to be healthy mentally and physically. Mainly parents and schools have a major role to address this issue by educating the children about the pros and cons of food ads and restrict them from being addicted to online medias and tele vision programs since these are the major source of advertisements.

\section{REFERENCES}

[1] Arcan, C. (2013). Television and TV advertisements Influences on Chldren's Eating Behaviour. Encyclopaedia on Early Childhood Development.

[2] B Elbel, J. G. (2011). Child and adolescent fast-food choice and the influence of calorie labellling: a natural experiment. International Journal of Obesity.

[3] Bidget P. Kelly, L. K. (2015). The Impact of Marketing of Junk Foods on Children's Diet and Weight. In L. K. 
Bidget P. Kelly, The Impact of Marketing of Junk Foods on Children's Diet and Weight.

[4] Christy, B. (n.d.). Thei is Your Body on Fast Foods. The Washington Post.

[5] Hu, L., \&Bentler, P.M. (1999). Cutoff criteria for fit indices in covariance structure analysis: Conventional criteria versus new alternatives.Structural Equation Modeling, 6, 1-55.

[6] Kalinowski, K.E. (2006). Using structural equation modeling to conduct confirmatory factor analysis.

[7] Mark A Pereira, A. K. (Jan 2005). Fastfood habits, weight gain, and insulin resistance ( the CARDIA study): 15year prospective analysis. The Lancet, 36-42.

[8] Mark Keith Farady, S. V. (2016). Impace of Television Food Adverising on Unhealthy Food preferences and Eating Behaviour among Children: A Systematic Review. international journal of home science.

[9] Sadhguru, I. (2013, August 7). Youth and Indian Culture.

[10] Tripathi, V. (2016). impact of online marketing on teenagers in india. nternational journal of science and management.
[11] Vijayalakshmi, M. K. (2016). Impact of TeleVision Advertising on Unhealthy Food Preferences and Eating Behaviours among Children: A Systematic Review. International Journal of Home Science.

[12] Virendra Nath Misra, P. K. (2016). Evaluation of the Effect of Junk Foods on the Health of the School Children in Delhi. Indian Institute of Public Administration, New Delhi.

[13] C.M. Thakar, S.S. Parkhe, A. Jain etal., 3d Printing: Basic principles and applications, Materials Today: Proceedings, https://doi.org/10.1016/j. matpr.2021.06.272

[14] Khan, R. M. I., Kumar, T., Supriyatno, T., \&Nukapangu, V. (2021). The Phenomenon of Arabic-English Translation of Foreign Language Classes During The Pandemic. IjazArabi Journal of Arabic Learning, $4(3)$.

https://doi.org/10.18860/ijazarabi.v4i3. 13597

[15] Sajja, G., Mustafa, M., Phasinam, K.,Kaliyaperumal, K., Ventayen, R., \&amp; Kassanuk, T. (2021). Towards Application of Machine Learning in 
Classification and Prediction of Heart

Disease. 2021 Second International

Conference On Electronics And

Sustainable Communication Systems

(ICESC).https://doi.org/10.1109/icesc5

$\underline{1422.2021 .9532940}$

16. Veluri, R., Patra, I., Naved, M., Prasad, V.,Arcinas, M., Beram, S., \&amp; Raghuvanshi, A. (2021). Learning analytics using deep learning techniques for efficiently managing educational institutes. Materials Today: Proceedings.

https://doi.org/10.1016/j.matpr.2021.11.416 17.wikipedia.(2018).https://en.wikipedia .org/wiki/Junk_food. Retrieved from Wikipedia 